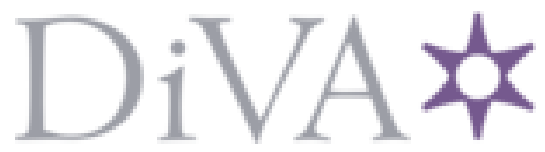

http://www.diva-portal.org

This is the published version of a paper presented at TEI '21: Proceedings of the Fifteenth International Conference on Tangible, Embedded, and Embodied Interaction.

Citation for the original published paper:

Núñez-Pacheco, u. (2021)

Tangible Body Maps of Felt-Sensing Experience

In:

https://doi.org/10.1145/3430524.3442700

N.B. When citing this work, cite the original published paper.

Permanent link to this version:

http://urn.kb.se/resolve?urn=urn:nbn:se:kth:diva-293343 


\title{
Tangible Body Maps of Felt-Sensing Experience
}

\author{
Claudia Núñez-Pacheco \\ KTH Royal Institute of Technology \\ claudia2@kth.se
}

\begin{abstract}
There is a growing interest amongst the HCI community to access and articulate the core of experiences for design use. The premise is that, by accessing detailed accounts of everyday experiences, we can obtain refined material for the design of interactive systems more connected with our bodies and emotions. This TEI studio aims to introduce participants to the basis of phenomenologically grounded techniques in combination with the use of tangible materials as a way to articulate experience from the inner self, applied to the evaluation of existing technologies. This studio offers an alternative to assessment tools that rely on a predefined repertoire of feelings, to instead focus on emergent, complex and unclear aspects of our emotions. These strange collections of emotions -or felt senseswill be further explored through self-reporting tools and group exercises.
\end{abstract}

\section{CCS CONCEPTS}

- Human-centered computing; • Interaction design; • Interaction design process and methods;

\section{KEYWORDS}

HCI, Evaluation methods, Soma Design, Focusing

\section{ACM Reference Format:}

Claudia Núñez-Pacheco. 2021. Tangible Body Maps of Felt-Sensing Experience. In Fifteenth International Conference on Tangible, Embedded, and Embodied Interaction (TEI '21), February 14-17, 2021, Salzburg, Austria. ACM, New York, NY, USA, 3 pages. https://doi.org/10.1145/3430524.3442700

\section{DETAILED PROPOSAL DESCRIPTION}

This studio offers an exploration of a series of research methods grounded in first-person and second-person perspectives, including an open-ended use of readily available materials. Tangible Body Maps -this is, the combination of body maps, tangible materiality and methods - will be used to evaluate and describe experiences in non-prescriptive, yet rich ways. Evaluation exercises will be focused on two main dimensions: (1) First, towards the description of autobiographical, everyday experience, and (2) our experiences with a specific piece of digital technology, which will be examined through the lens of introspection. These introspective examinations will be discussed within the group towards expanding our subjective view

Permission to make digital or hard copies of part or all of this work for personal or classroom use is granted without fee provided that copies are not made or distributed for profit or commercial advantage and that copies bear this notice and the full citation on the first page. Copyrights for third-party components of this work must be honored

For all other uses, contact the owner/author(s).

TEI '21, February 14-17, 2021, Salzburg, Austria

(c) 2021 Copyright held by the owner/author(s).

ACM ISBN 978-1-4503-8213-7/21/02.

https://doi.org/10.1145/3430524.3442700
The premise behind this studio responds to Eugene Gendlin's proposition that the body knows its situation, and it does even before we are able to articulate the reasons behind this [5]. For instance, that sense of estrangement that emerge when we see an unknown face that seems familiar to us, or when we avoid certain situations based on what we normally identify as our gut feelings are some examples of evaluative responses that emerge naturally. Through this studio, we aim to explore tools that allow us to clearly describe the underlying qualities of everyday situations, accessing a kind of knowledge that is generally overlooked due to its complexity, but that we capture as a useful evaluative tool in the design process. These qualities embodied are called felt senses, and are described as follows:

"A felt sense is not a mental experience but a physical one. A bodily awareness of a situation or person or event. An internal aura that encompasses everything you feel and know about the given subject at a given time - encompasses it and communicates it to you all at once rather than detail by detail. Think of it as a taste, if you like, or a great musical chord that makes you feel a powerful impact, a big round unclear feeling... A felt sense doesn't come to you in the form of thoughts or words or other separate units, but as an ingle (though often puzzling and very complex) bodily feeling [5](p.32).

We capture the principle that the body is the gateway to access the felt sense, therefore important part of the activities will be centred on the notion of paying attention to the changes occurring in our somas, and how these are described. For this studio, we rescue the concept of active externalism as described by Clark and Chalmers, which defies traditional ideas of the mind [2]. This active externalism refers to how cognition is distributed outside bodily limits through the use of external tools, as well as the use of language. Consequently, we use artefacts as tools that project part of our thoughts and feelings, facilitating the emergence of tacit discoveries after examination. In this studio, artefacts will take the shape of body maps and their tangible material representations, encapsulating open-ended narratives for participants to uncover. We will use both the Focusing technique [5] and active listening [14] to obtain detailed descriptions of how these artefacts respond to the feelings of estrangement facilitated through the exercises [10]. Participants will use Focusing as a self-reporting technique, documenting on their findings from a first-person perspective. In contrast, active listening is framed within a second person stance, [17] and will be used to empathically connect with the other towards revealing implicit information in a non-judgmental way.

\section{A NEED FOR NEW METHODS AND TOOLS FOR ARTICULATING EXPERIENCE}

There is a growing interest amongst the HCI community to access and articulate the core of experience for design use. The premise is that, by accessing detailed accounts of everyday experience, we can obtain refined material for the design of interactive systems 
more connected with our bodies and emotions [6]. In the last few years, a myriad of methods imported from other disciplines have been used towards pursuing the access to rich accounts, such as micro phenomenology in conjunction with VR [13], body maps and Soma Design [6], autobiographical diaries [3], Feldenkrais [9] and Focusing as an ideation method [12]. However, the exploration of these tools is still marginal, despite the crescent interest of our community to access more somatic and experience-oriented research tools. Predominantly, widespread methods of emotion assessment offer a predefined repertoire of responses for instance [1,16], which, although have been proven useful for HCI research, might leave out some other detailed aspect of our aesthetic experiencing.

Another essential aspect behind exploring methods grounded in phenomenology and material exploration is the need for tools allowing design teams to engage in critical discussions as part of the evaluation of prototypes. In this regard, the exploration of first and second person methods [15] connect us back with pedagogical practices of design, where the studio acts a space for discussion and creativity [8], an aspect that appear as sometimes diluted in more user-centric views.

In this studio, we offer a novel exploration of the use of tangible materials and Focusing as a technique for evaluation. By body maps, we refer to pictorial representations of embodied information, which have been traditionally used in the humanities, lately disseminated across HCI research [4]. As a precedent, our proposal follows the tradition of previous attempts to generate cross-culturally valid methods of evaluation [7]. In this studio, however, we introduce somatic and existential approaches that will better equip participants to describe the abstract representations derived from their evaluation of experiences with technology and materials.

\section{MATERIALS TO BE EXPLORED}

For accessibility purposes, we will work with low cost and readily available materials such as plasticine, printed body maps and felttip coloured pens, which have to be purchased in advanced by the participants. Taking into account travel restriction and quarantines imposed in certain countries, certain stationeries can be replaced by materials available at home (such as dough instead of plasticine, or coloured pencils instead of felt-tip pens, for instance). If available, we encourage the use of tablets for drawing and note taking over printed material. Templates and some reading material will be sent via email. Participants should also have a camera or smartphone to take photographs of their explorations.

\section{LEARNING GOALS}

Participants will be introduced to the somatic technique Focusing [5], where they will learn a tool to access their tacit meaning by paying attention to their bodies and emotion. Additionally, they will experiment with ways to articulate experience by using tangible materials as projective artefacts of the self. To further understand the nuances of body maps and their tangible manifestations, participants will also be introduced to the Active Listening technique [14], which will be practised in pairs.

Emerging aesthetic qualities will be explored and discussed from the standpoint of the following aspects:
- Evaluation of our experiences with technologies from an angle that focuses on embodied inner presence [11].

- The emergence of insights - In some cases, participants experience them directly.

Additionally, participants will learn:

- What is felt sensing, and how this concept is relevant to HCI.

- A simultaneous exploration of hands-on methods that incorporate tangible materials and open-ended tools, allowing its use in multicultural contexts [4, 7]

- Ways of extracting phenomenological information grounded in bodily self-awareness.

\section{SCHEDULE}

\subsection{Day 1 - Introduction to Tangible Body Maps and Focusing (3.5 hours)}

- Opening: Presentation of organisers and program.

- Presentations: Participants will be asked to prepare a brief presentation about their work as a practitioner and/or researcher, and how accessing inner experience becomes relevant. Presentations of work at early stages and/or at a conceptual level are also welcome.

- Introduction to the Focusing Technique, and some applications in research.

- The Love Exercise: Accessing the complexities of inner experience.

- Body maps and Tangible Body Maps: Crafting from experience.

- Presentation of results and group discussion.

\subsection{Day 2 - Evaluating experience (3.5 hours)}

- Focusing and tangible body maps to evaluate experience with an existing piece of digital technology.

- Getting to the core of experience: The active listening technique.

- Archetypes of participants: Applying a Focusing-oriented tool for brief analysis.

- Discussion: Lessons learnt and applications.

\section{PLAN FOR THE VIRTUAL CONFERENCE}

The studio is planned as a two-day virtual event over Zoom, with slots of three hours respectively. Activities have been split into two sessions, aiming that participants will digest the insights emerging during each session. Online tools such as Padlet and Miro will be used to allow more dynamic discussions on contributions made by the participants, including body maps and their tangible representations.

\section{REFERENCES}

[1] Margaret Bradley and Peter Lang. 1994. Measuring emotion: The self-assessment manikin and the semantic differential. Journal of Behavioral Therapy and Experimental Psychiatry, 25, 49-59.

[2] Andy Clark and David Chalmers. 1998. The Extended Mind. Analysis, 58(1), 7-19. Retrieved October 28, 2020, from http://www.jstor.org/stable/3328150

[3] Audrey Desjardins and Aubree Ball. 2018. Revealing Tensions in Autobiographical Design in HCI. In Proceedings of the 2018 Designing Interactive Systems Conference (DIS '18). Association for Computing Machinery, New York, NY, USA, 753-764. DOI:https://doi.org/10.1145/3196709.3196781 
[4] Denise Gastaldo, Natalia Rivas-Quarneti and Lilian Magalhaes. 2018. Body-Map Storytelling as a Health Research Methodology: Blurred Lines Creating Clear Pictures. Forum Qualitative Sozialforschung / Forum: Qualitative Social Research, 19(2). DOI:http://dx.doi.org/10.17169/fqs-19.2.2858

[5] Eugene Gendlin. 1978. Focusing. Random House Digital, Inc.

[6] Kristina Höök. 2018. Designing with the body: Somaesthetic interaction design MIT Press.

[7] Katherine Isbister, Kristina Höök, Michael Sharp, and Jarmo Laaksolahti. 2006. The sensual evaluation instrument: developing an affective evaluation tool. In Proceedings of the SIGCHI Conference on Human Factors in Computing Systems (CHI '06). Association for Computing Machinery, New York, NY, USA, 1163-1172. DOI:https://doi.org/10.1145/1124772.1124946

[8] Jon Kolko. 2011. Endless nights-learning from design studio critique. Interactions 18(2): 80-81. DOI:https://doi.org/10.1145/1925820.1925838

[9] Wonjun Lee, Youn-kyung Lim, and Richard Shusterman. 2014. Practicing somaesthetics: exploring its impact on interactive product design ideation. In Proceedings of the 2014 conference on Designing interactive systems (DIS '14). Association for Computing Machinery, New York, NY, USA, 1055-1064. DOI:https://doi.org/10.1145/2598510.2598561

[10] Claudia Núñez Pacheco and Lian Loke. 2017. Tacit Narratives: Surfacing Aesthetic Meaning by Using Wearable Props and Focusing. In Proceedings of the Eleventh International Conference on Tangible, Embedded, and Embodied Interaction (TEI '17). Association for Computing Machinery, New York, NY, USA, 233-242. DOI:https://doi.org/10.1145/3024969.3024979
[11] Claudia Núñez-Pacheco. 2018. Reflection through Inner Presence: A Sensitising Concept for Design. Multimodal Technogies and Interaction. 2, no. 1: 5. DOI:https: //doi.org/10.3390/mti2010005

[12] Claudia Núñez-Pacheco and Lian Loke. 2018. Towards a technique for articulating aesthetic experiences in design using Focusing and the Felt Sense, The Design Journal, 21:4, 583-603, DOI:https://10.1080/14606925.2018.1467680

[13] Mirjana Prpa, Sarah Fdili-Alaoui, Thecla Schiphorst, and Philippe Pasquier. 2020. Articulating Experience: Reflections from Experts Applying MicroPhenomenology to Design Research in HCI. In Proceedings of the 2020 CHI Conference on Human Factors in Computing Systems (CHI '20). Association for Computing Machinery, New York, NY, USA, 1-14. DOI:https://doi.org/10.1145/ 3313831.3376664

[14] Carl Rogers and Richard Farson. 1979. Active listening. Organisational Psychology, $168-180$

[15] Thecla Schiphorst. 2011. Self-evidence: applying somatic connoisseurship to experience design. In CHI '11 Extended Abstracts on Human Factors in Computing Systems (CHI EA '11). Association for Computing Machinery, New York, NY, USA, 145-160. DOI:https://doi.org/10.1145/1979742.1979640

[16] Martin Tomitsch, Cara Wrigley, Madeleine Borthwick, Naseem Ahmadpour, Jessica Frawley, A. Baki Kocaballi, Claudia Núñez-Pacheco, Karla Straker and Lian Loke. 2018. Design. Think. Make. Break. Repeat.: A handbook of methods. Amsterdam: BIS

[17] Francisco Varela and Jonathan Shear. 1999. First-person Methodologies: What, Why, How?. in F. Varela and J. Shear (Eds), The View from Within, pp. 1-14 